\title{
Cost-Effectiveness of Follow-Up of Chronic Coughers in Detecting Smear-Positive Tuberculosis in South Ethiopia
}

\section{Endrias Markos \\ Woldesemayat (iD}

School of Public Health, College of Medicine and Health Sciences, Hawassa University, Hawassa, Ethiopia
Correspondence: Endrias Markos

Woldesemayat

Email endromark@yahoo.com
Introduction: In Ethiopia, no studies assessing the cost-effectiveness of follow-up of smear-negative chronic coughers in detecting smear-positive tuberculosis (TB) $(\mathrm{PTB}+)$ cases have been reported.

Objective: This article describes the cost-effectiveness of community-based follow-up of smear-negative chronic coughers in detecting PTB + cases.

Methods: Two alternative strategies of TB case finding, namely community-based follow-up of smear-negative chronic coughers and passive TB case finding, were compared. Participants were selected randomly in the active TB case finding approach, while purposively in the passive TB case finding strategy. In November 2012 and January 2015, costs related to TB diagnosis were collected using structured questionnaires from sample of 60 patients in each strategy. Data on health system cost and direct and indirect costs incurred by patients and their caretakers were collected in Ethiopian Birr and converted into USD for analysis. Exchange rate for the data collection period of chronic coughers was $1 \mathrm{USD}=18.16 \mathrm{ETB}$ and for passive case finding period was 1 USD $=20.24$ ETB. Cost-effectiveness was calculated in terms of cost per PTB + cases detected.

Results: The overall cost of TB case finding was lower under active case finding approach than under passive TB case finding approach (USD 27.4 vs. 27.6). Active case finding approach was cost-effective by $43.4 \%$ and it is highly cost-effective when the duration of follow-up is reduced to 7 months or less.

Conclusion: Active case finding approach is a cost-effective approach of TB case finding. The cost benefit obtained could be even higher when the follow-up duration is minimized.

Keywords: cost, effectiveness, chronic coughers, smear-positive TB

\section{Introduction}

The incidence of all forms of tuberculosis (TB) in Ethiopia was 140/10 ${ }^{5}$ in 2019 . $^{1}$ According to the 2011 national TB prevalence survey, prevalence of smear-positive TB (PTB+) was $108 / 100,000 .^{2}$ Low socio-economic condition is one of the contributing factors for acquiring TB infection, ${ }^{3}$ developing the disease ${ }^{4-6}$ and low TB case detection. ${ }^{7}$ Despite "free service" for TB care, TB patients incur substantial cost for care seeking and treatment. ${ }^{8}$ The disease imposes high economic burden on the poor households for seeking TB care. ${ }^{9-13}$

In Ethiopia, sputum microscopy is the standard way of diagnosis of pulmonary TB and Directly Observed Treatment Short course (DOTS) is the standard approach 
for its treatment. ${ }^{14}$ Despite the implementation of DOTS, low case findings persisted to be the challenge of TB care in southern Ethiopia.

Delay in diagnosis is the main reason of low TB case finding, which could be related to low income, use of traditional medicines, low health-seeking behaviour, inaccessibility of diagnostic facilities and weak screening system. ${ }^{7,15,16}$ Active case finding of TB aims to minimize such barriers with an ultimate goal of reducing TB transmission. ${ }^{17}$ The main study showed that, communitybased follow-up of smear-negative people with cough of two weeks or more improves $\mathrm{PTB}+$ case detection. A detailed description of the study is published elsewhere. $^{18}$

In Ethiopia, no studies assessing the cost-effectiveness of follow-up of smear-negative people with cough of two weeks or more in detecting $\mathrm{PTB}+$ case have been reported. Conducting cost-effectiveness study is useful before implementation of any new intervention in the society. In this study, comparison of the cost effectiveness of diagnosis of TB under community-based follow-up of smearnegative people with cough of two weeks or more and passive TB case finding was done. The objective of the study was to investigate the cost-effectiveness of followup of smear-negative people with cough of two weeks or more in detecting PTB + cases which could help in improving TB control program in South Ethiopia.

\section{Methods}

\section{Study Setting}

This study was conducted in six rural communities of Dale district. Dale district is one of the 19 districts in Sidama zone, South Ethiopia. In 2011, the district has a population of above 250,000 people. It consists of rural people, settled for one or more years, who are mainly farmers. TB is one of the major public health problems in the district and its diagnosis is primarily carried out in health centers and hospitals.

\section{Design and Population}

Comparison of costing implication of active TB case finding and passive TB case finding was done. Under an active TB case finding approach, follow-up of chronic coughers (people with cough of two or more weeks) at community level was done and these cases were screened for TB. Every third or fourth month we interviewed them and did sputum investigations as required. The objective of the study was to evaluate the usefulness of communitybased follow-up of smear-negative chronic coughers in detecting PTB + cases, where participants were followed for 10 months. Details of the study are available elsewhere. ${ }^{7}$ Under passive TB case finding schemes, patients with TB suggestive symptoms went to health facilities (health centers or hospitals) for TB diagnosis through self-referral or using advises patients obtained from health extension workers. Then TB cases were detected in health facilities among the self-referred patients.

Participants of this study were a sample of 60 randomly selected smear-negative chronic coughers, who were involved in a cohort study ${ }^{7}$ and another 60 PTB+ patients detected by a passive TB case finding approach, living in the same communities with the smear-negative chronic coughers. A list of smear-negative chronic coughers by kebele (community with an average population of 5000 people) was used to select study participants for active case finding approach (10 per community). A TB treatment register was used to recruit TB patients from the health facilities. Random sampling was used to select participants for active TB case finding approach. TB patients who were on DOTS during the period of data collection were included in the study under the passive TB case finding approach. TB patients for each community were recruited from TB registry found in health posts.

\section{Costing}

The mean cost value was calculated by dividing total cost values by total number of patients involved in the study. Patient costs includes costs used for buying medications, transportation costs, costs expended by the patient for buying of food and drinks, indirect costs and the cost used for an accompanying person. Direct cost implies outof-pocket expenses for patients or an accompanying person during follow-up for diagnosis of TB. Indirect cost is the sum of costs due to loss of time by the patient or caretakers (working days lost due to travel time and staying in health facilities). Time spent in health facilities is converted in to money based on unskilled wage rate during the study period in the study area, which was 30 ETB (1.6 USD) per day for the chronic coughers and 35 ETB (1.7 USD) per day for TB patients involved from passive case finding. Capital investment cost includes costs used for construction of buildings, buying cars and motorcycles. Running cost reflects cost incurred by health facilities for consumption of electricity, water, telecommunication, 
medicine transport, buying microscope and other laboratory equipment, buying furniture, buying other materials and services and training cost. Training cost includes costs used for TB-related training of health professionals which is invested by the district health office or each health facility. Program cost is the sum total of capital investment cost, running cost and salaries paid for personnel working in the health facilities. In addition to these costs it includes research cost expended for the patients under active TB case finding approach. Research cost is the cost expended for personnel (data collectors, supervisors and laboratory technicians), stationery cost, transport cost, printing and duplication. Total cost is the sum of patient cost, caretakers' cost and program cost. Under both strategies, average costs for specific cost items is calculated as the total cost of the item divided by total quantity of the item used or participants involved in the study. Costing annuitization was done; 30 years for buildings, 10 years for cars and equipment and 5 years for motorcycle.

To collect patients and caretakers' costs data, data collectors interviewed smear-negative chronic coughers, TB patients and their caretakers. Health system cost data was obtained through interviewing the health care provider. Data were collected in November 2012 for the active TB case finding approach. Data for the passive TB case finding was collected in January 2015. All costing data were collected, entered in to computer and analyzed in ETB. Then the output values were converted in to USD at the official exchange rate of the National Bank of Ethiopia for the data collection period of $1 \mathrm{USD}=18.16 \mathrm{ETB}$ for the chronic coughers and 1USD $=20.24$ ETB for the passively identified TB cases.

Success in follow-up was calculated based on the midtime population. Of 724 smear-negative chronic coughers who began their follow-up in 2012, 15 died and 7 missed their follow-ups. So 701 smear-negative chronic coughers were evaluated at the end of the cohort, which gave us 713 mid-time populations for the active TB case finding approach. During the same period, the total number of people among whom $\mathrm{PTB}+$ cases could have been detected passively was 19,496 . For this group, the assumption was made as a $99.9 \%$ successful follow-up rate, which was the rate of successful follow-ups for neighbourhood controls in the cohort study. ${ }^{18}$ This gives 19,441 people who could have been evaluated at the end of the cohort under the passive TB case finding approach. Thus, the mid-time population for this group was 19,469.
Effectiveness was defined based on the number of PTB + cases diagnosed in each strategy. It was 23 patients under smear-negative chronic cougher's follow-up approach. Number of $\mathrm{PTB}+$ cases detected through TBREACH project and passive TB case finding was 30 . Then, the 2010/2011 case detection rate of PTB+ in SNNPR was considered which was $48.4 \%{ }^{19}$ With this assumption, about $15 \mathrm{PTB}+$ cases could have been detected through passive TB case finding approach in the study communities. Cost-effectiveness was calculated as the average cost per number of $\mathrm{PTB}+$ cases identified in each TB case finding approach. The denominator for this calculation was 23 PTB + patients under active TB case finding approach and $15 \mathrm{PTB}+$ patients under passive $\mathrm{TB}$ case finding approach. For each TB case finding method, the cost-effectiveness of each phase of the follow-up was calculated as the average cost in the specified phase of the cohort per number of $\mathrm{PTB}+$ cases detected in each phase of the follow-up. In both strategies, the average cost of each phase of the follow-up was calculated from the total cost (total cost of the strategy/10 months * 4 months or total cost of the strategy/10 months $* 7$ months). Number of $\mathrm{PTB}+$ cases for each phase of the follow-up was obtained from the main study ${ }^{18}$ for active TB case finding approach and calculated from the $30 \mathrm{PTB}+$ patients detected for the passive TB case finding approach. A costeffectiveness ratio was calculated as the net cost divided by the number of TB cases detected in each strategy.

A one way sensitivity analysis of cost-effectiveness was performed to investigate how cost-effectiveness was sensitive to variations in the costs per TB case finding. The uncertainty analyses were based on the minimum and maximum values of selected characteristics. We varied one cost variable at a time. We considered an input value of $3 \%$ discount rate and the lower and upper limits of $95 \%$ confidence interval of the case detection rate of an active TB case finding approach in the sensitivity analysis.

\section{Ethical Clearance}

Ethical approval was granted by the Ethical Review Committee for the Health Research of Southern Nations Nationalities and Peoples' Regional State Health Bureau in Ethiopia (ethical clearance number 902-6-19/13). The study was conducted in accordance with the Declaration of Helsinki. Participants' information was anonymized and informed consent was obtained from all respondents. 


\section{Results}

\section{Socio-Demographic Characteristics}

The mean (standard deviation [SD]) of age was 45.5 (18.4) years for people involved in an active TB case finding approach, and it was 31.0 (12.1) years for patients detected though a passive TB case finding approach. More women were enrolled under an active TB case finding approach (61.7\%; 37 of 60 patients) than under a passive TB case finding approach $(48.3 \%$; 29/60). Regarding literacy, $71.7 \%(43 / 60)$ of the smear-negative chronic coughers and $50 \%(30 / 60)$ of the TB patients were illiterate. The majority of study participants $(88.3 \% ; 53 / 60)$ of the smear-negative chronic coughers and $75 \%(45 / 60)$ of the TB patients were married. Characteristics like marital status, education, occupation, type of health facility visited showed variation among the two groups (Table 1).

\section{Cost}

The mean (SD) of patients' health facility travel times was 4.4 (1.2) days for peoples involved under active TB case finding approach and 4.4 (1.0) days for patients involved under passive TB case finding modality. Smear-negative chronic coughers frequently travelled to health posts $52 / 99$ visits (52.5); while patients under the passive TB case finding modality frequently travelled to health centers 60 / 135 visits (44.4\% of the total visit). Total patient cost (direct and indirect cost) was higher under an active TB case finding approach (USD 19.7) than under a passive TB case finding approach (USD 18.8). Total caretakers cost under active TB case finding approach was less costly (USD 7.7 vs. 8.0). Overall patient and caretaker costs under an active TB case finding approach was lower than under a passive TB case finding approach (USD 27.4 Vs 27.6). Program costs, which includes costs such as salaries, running costs and capital investment costs, for active case finding approach was lower (USD 582 vs. 681) Table 2.

\section{Effectiveness}

Under the active TB case finding scheme, 713 smearnegative chronic coughers were successfully followed for 10 months and 23 (3.1\%) developed PTB+, while under passive TB case finding modality, 19,469 people were followed for the same duration and 15 PTB + cases could have been detected. Community-based follow-up of smear-negative chronic coughers was effective in detecting more $\mathrm{PTB}+$ cases than the routine facility-based passive $\mathrm{TB}$ case finding.
Table I Characteristics of Study Participants

\begin{tabular}{|c|c|c|c|}
\hline Characteristics & $\begin{array}{c}\text { Active } \\
\text { Case } \\
\text { Finding } \\
\mathbf{N}^{\circ}(\%)\end{array}$ & $\begin{array}{c}\text { Passive } \\
\text { Case } \\
\text { Finding } \\
\mathbf{N}^{\circ}(\%)\end{array}$ & P-value \\
\hline Age, mean (SD) & $45.5(18.4)$ & $31.0(12.1)$ & \\
\hline \multicolumn{4}{|l|}{ Sex } \\
\hline Male & $23(38.3)$ & 31 (5I.7) & 0.14 \\
\hline Female & 37 (6।.7) & $29(48.3)$ & \\
\hline \multicolumn{4}{|l|}{ Marrital status } \\
\hline Single & $5(8.3)$ & $15(25.0)$ & 0.02 \\
\hline Married & $53(88.3)$ & $45(75.0)$ & \\
\hline Widowed & $2(3.3)$ & $0(0)$ & \\
\hline \multicolumn{4}{|l|}{ Education } \\
\hline No education & 43 (7I.7) & $30(50.0)$ & 0.05 \\
\hline Primary education & $14(23.3)$ & $25(4 \mid .7)$ & \\
\hline Secondary education & $3(5.0)$ & $5(8.3)$ & \\
\hline \multicolumn{4}{|l|}{ Occupation } \\
\hline Farmer & $19(31.7)$ & $19(31.7)$ & 0.03 \\
\hline House wife & $35(58.3)$ & $24(40.0)$ & \\
\hline Student & $6(10.0)$ & $12(20.0)$ & \\
\hline Merchant & & $5(8.3)$ & \\
\hline \multicolumn{4}{|l|}{$\begin{array}{l}\text { Type of health facility } \\
\text { visited }\end{array}$} \\
\hline Health post & $52(52.5)$ & $33(24.4)$ & $<0.00$ \\
\hline Health center & $33(33.3)$ & $60(44.4)$ & \\
\hline Traditional healer & $0(0)$ & $21(15.6)$ & \\
\hline Hospital & $10(10.1)$ & $4(3)$ & \\
\hline Other & $4(4)$ & $17(12.6)$ & \\
\hline Total & $99(100)$ & $135(100)$ & \\
\hline $\begin{array}{l}\text { Patients health facility visit } \\
\text { times, mean (SD) }\end{array}$ & $4.4(1.2)$ & $4.4(1.0)$ & \\
\hline $\begin{array}{l}\text { Patient transport time, } \\
\text { mean }(\mathrm{SD})^{*}\end{array}$ & $\begin{array}{c}176.1 \\
(106.9)\end{array}$ & $177.3(47.7)$ & \\
\hline $\begin{array}{l}\text { Caretaker accompanied } \\
\text { patient times, mean (SD)* }\end{array}$ & $1.7(0.9)$ & $2.3(0.8)$ & \\
\hline $\begin{array}{l}\text { Caretaker transport time } \\
\text { spent, mean }(\mathrm{SD})^{*}\end{array}$ & $83.9(77.6)$ & $91.4(34.0)$ & \\
\hline
\end{tabular}

Note: *Time in minutes.

Abbreviation: SD, standard deviation.

\section{Cost-Effectiveness}

Program costs per successfully detected TB cases was USD25.3 under an active TB case finding approach and USD 45.5 under passive TB case finding approach. Patient and caretaker costs per successfully detected TB cases were lower under active TB case finding approach than 
Table 2 Average Cost per Patient in USD for TB Case Finding Modalities

\begin{tabular}{|l|c|c|c|c|}
\hline \multirow{2}{*}{ Characteristics } & \multicolumn{2}{c|}{$\begin{array}{c}\text { Active Case } \\
\text { Finding }\end{array}$} & \multicolumn{2}{c|}{$\begin{array}{c}\text { Passive Case } \\
\text { Finding }\end{array}$} \\
\cline { 2 - 5 } & Quantity & $\begin{array}{c}\text { Mean } \\
\text { Unit }\end{array}$ & Quantity & $\begin{array}{c}\text { Mean } \\
\text { Unit }\end{array}$ \\
& & Price & & Price \\
\hline Running cost & 60 & 222.8 & 60 & 248.0 \\
Salaries & 60 & 330.1 & 60 & 389.1 \\
Capital investment & 60 & 29.6 & 60 & 44.6 \\
Total program cost & 60 & 582.5 & 60 & 681.8 \\
Patient direct cost & 45 & 12.4 & 60 & 10.8 \\
Patient indirect cost & 60 & 7.3 & 60 & 8.0 \\
Total patient cost & 60 & 19.7 & 60 & 18.8 \\
Caretaker direct cost & 22 & 4.9 & 21 & 3.9 \\
Caretaker indirect cost & 27 & 2.8 & 21 & 4.1 \\
Total caretaker cost & 27 & 7.7 & 21 & 8.0 \\
Total patient and caretaker cost & 60 & 27.4 & 60 & 27.6 \\
Research cost & 713 & 3.7 & 60 & 0.0 \\
Total cost & 60 & 613.6 & 60 & 708.6 \\
\hline
\end{tabular}

Abbreviation: USD, United States Dollar.

under passive TB case finding approach (USD 0.9 vs. 1.3) and (USD 0.3 vs. 0.5), respectively (Table 3). Total cost per successfully detected TB cases for the whole duration was USD 26.7 under active TB case finding approach and USD 47.2 under passive TB case finding approach. In a short term follow up ( 4 months or 7 months), the cost per successfully detected TB cases under passive TB case

Table 3 Cost-Effectiveness of Community-Based Follow-Up of Chronic Coughers

\begin{tabular}{|l|c|c|}
\hline Expenditure & Active Case Finding & Passive Case Finding \\
\hline Program cost & 25.3 & 45.5 \\
Patient cost & 0.9 & 1.3 \\
Caretakers cost & 0.3 & 0.5 \\
Research cost & 0.2 & 0.0 \\
Overall CER & 26.7 & 47.2 \\
\hline
\end{tabular}

Abbreviation: CER, cost effectiveness ratio. finding modality was about three times higher than the cost per successfully detected TB cases under active TB case finding approach (see Table 4).

\section{Sensitivity Analysis}

The sensitivity analysis showed that an active TB case finding approach was found to be cost-effective compared to the passive approach on varying estimates of different cost items (Table 5).

\section{Discussion}

According to the cost-effectiveness analysis, the strategy community-based follow-up of smear-negative chronic coughers, could be classified as a less costly and highly cost-effective approach of TB case finding. This was true particularly from the perspectives of care takers cost and program cost. Compared to passive TB case finding, community-based follow-up of smear-negative chronic coughers was cost-effective approach of TB case finding by $23.7 \%$ from the perspective of program cost, by $46.2 \%$ from the perspective of patient cost and by $40 \%$ from the perspective of caretaker cost.

Moreover, the new approach was highly cost-effective when the duration of follow-up is minimized to 7 months or less. This could be due to more TB cases being detected in the early phase of the follow-up than in the later phases. The number of patients diagnosed with TB reduces as time goes. Therefore, persistency of cough among majority of chronic coughers, as the follow-up duration increases is most likely related to other chronic disease than TB. This finding suggests us follow-up of chronic coughers for 7 months or less is a relatively better duration in terms of the cost and the cost-effectiveness.

The low number of times patients visit health facilities and a decreased in the distance where patients go for the diagnosis of TB under community-based follow-up of smear-negative chronic coughers approach were the main reasons for the present finding. Patients under smear-

Table 4 Cost-Effectiveness of Community-Based Follow-Up of Chronic Coughers in Different Phases of the Cohort

\begin{tabular}{|l|c|c|c|c|c|c|c|c|}
\hline \multirow{2}{*}{ Time } & \multicolumn{3}{|c|}{ Active Case Finding } & \multicolumn{4}{c|}{ Passive Case Finding } \\
\cline { 2 - 9 } & PTB+ Cases & Cost & CER & CCER & PTB+ Cases & Cost & CER & CCER \\
\hline 4 months & 8 & 245.44 & 30.7 & 30.7 & 3.5 & 283.4 & 81.0 & 81.0 \\
7 months & 8 & 184.08 & 23.0 & 15.3 & 2.5 & 212.6 & 85.0 & 82.7 \\
I0 months & 7 & 184.08 & 26.3 & 26.7 & 9 & 212.6 & 23.6 & 47.2 \\
Total & 23 & 613.6 & 26.7 & 26.7 & 15 & 708.6 & 47.2 & 47.2 \\
\hline
\end{tabular}

Abbreviations: CER, cost effectiveness ratio; CCER, cumulative cost-effectiveness ratio. 
Table 5 Variation in Cost-Effectiveness Ratio Upon Changes of Input Variables

\begin{tabular}{|l|c|c|c|c|c|c|}
\hline & \multicolumn{2}{|c|}{ Input Values } & \multicolumn{2}{c|}{ CER ACF } & \multicolumn{2}{c|}{ CER PCF } \\
\cline { 2 - 7 } & Min & Max & Min & Max & Min & Max \\
\hline Patient direct cost* & 0 & 81.3 & 0.0 & 35.3 & 0.0 & 54.2 \\
Patient indirect cost* & 3.2 & 15 & 1.4 & 6.5 & 14.1 & 10.0 \\
Caretaker direct cost* & 0.5 & 34.3 & 0.2 & 3.5 & 0.3 & 1.1 \\
Care take indirect cost* & 1.6 & 8 & 0.7 & 82 & 168.6 & 17.3 \\
Discount rate & 0 & 0.03 & 12.5 & 24.9 & 19.2 & 38.1 \\
Case detection rate** & 28.8 & 57.2 & & & 17.3 \\
\hline
\end{tabular}

Notes: Minimum and maximum costs for patients and caretakers are taken from the data. Discount rate $=3 \%$. ${ }^{*}$ ER $* 10$ for these variables. $* *$ Case detection rate $=23 / 56$ for CCFU and $48.4 \%$ for PCF.

Abbreviations: CER, cost effectiveness ratio; ACF, active case finding; PCF, passive TB case finding.

negative chronic coughers' follow-up approach visited health facilities 99 times while patients under passive TB case finding approach made a total of 135 facility visits. In this study majority of patients under follow-up of smearnegative chronic coughers approach went to health posts $(52.5 \%)$, which is located in their community. While under passive TB case finding approach majority of patients went to the health centers (44.4\%). In rural settings of southern Ethiopia, most health centers are located further away than health posts. In agreement to the current study, some studies reported that community-based approaches of TB care improved accessibility of TB care facilities to the people, thus it minimized the costs incurred on them for transport and other indirect costs..$^{20,21}$

In this study, the mean patient transport time was nearly the same under the two methods of TB case finding. Also, the mean caretakers transport time spent had small difference between the two approaches. The number of times smearnegative chronic coughers went to hospitals was 10 times ( $10.1 \%$ of the whole visits) while similar figures for patients under a passive TB case finding approach was 4 times (3\% of the whole visits). The higher SD of this variable under chronic coughers' follow-up approach supports our explanation for it. This may also be the reason for the caretakers' direct cost are higher under the chronic coughers' follow-up approach. Caretakers of patients who went to these hospitals might have had higher expense.

Despite the difference in their methodology, other studies also showed the cost-effectiveness of community-based TB case findings. ${ }^{21-27}$ The cost-effectiveness analysis differs from previous studies done for TB in that the comparison was community-based follow-up of smear-negative chronic coughers with the conventional passive TB case findings. Follow-up visit for smear-negative chronic coughers was carried out every 3 to 4 months. This gap may be too wide and made some PTB + cases may be missed in the surveys and diagnosed by another project that was carried out in the study area. ${ }^{28}$ Based on this, the author suggests that reducing the time of follow-up to every 2-4 weeks is better to catch all the PTB + cases in the follow-up and limit the transmission of TB within the communities. This may improve the costeffectiveness more than has been seen in the current study. In the TBREACH project they did follow-up visits every 2-4 weeks for each smear-negative chronic cougher they saw for the first time. ${ }^{28}$

\section{Strengths and Limitation}

One of the strengths of this study is that it included both the direct and indirect costs. In economic analysis, considering both the direct and indirect costs is more informative to policymakers to plan for a wider section of the community. Another strength was that program cost data was obtained from all health facilities that patients attended and the district health office. This minimized information bias which could occur if selected facilities were included in the study. A limitation seen in this study is that the investigator did not carry out adjustment of costs collected in two different periods for the two groups of patients. However, the interval between the two data collection periods was small (only two years) and the change in costings was low between the two data collection periods. Moreover, an official exchange rate of ETB to USD for each data collection period was considered in the analysis.

\section{Conclusion}

Community-based follow-up of smear-negative chronic coughers has lower cost and higher cost-effectiveness, which could help in improving PTB + case detection in rural communities of southern Ethiopia. This implies that 
with the same level of resources, more smear-positive TB patients could be detected in a community-based followup of smear-negative chronic coughers. The cost benefit obtained could be even higher when the follow-up duration is reduced to 7 months or less. However, increasing the frequency of follow-up to every $2-4$ weeks could help in early diagnosis of the PTB + cases, which could limit transmission of the disease in communities. The author believes that the finding of this study could be applicable in similar settings in Ethiopia or in other high TB burden countries. In addition to the passive TB case finding approach, chronic coughers follow-up could be implemented to early detect TB cases as it is a less costly and costeffective method. Chronic coughers' follow-up could save costs and lives.

\section{Abbreviations}

DOTS, Directly Observed Treatment Short course; HEWs, health extension workers; TB, tuberculosis; PTB + , smearpositive TB.

\section{Data Sharing Statement}

Data could be obtained from the author on request.

\section{Acknowledgments}

The author is grateful to the Sidama Zone Health Department, Dale district health office, the study participants, the health facilities involved in the study and the data collectors. The author also thanks the University of Bergen in Norway for funding the study.

\section{Author Contributions}

EMW made a significant contribution to the work reported, including the conception, study design, execution, acquisition of data, analysis and interpretation,; drafting, revising and critically reviewing the article; gave final approval of the version to be published; has decided on the journal to which the article has been submitted; and agrees to be accountable for all aspects of the work.

\section{Disclosure}

The author reports no conflicts of interest for this work.

\section{References}

1. World Health Organization. Global Tuberculosis Control Surveillance, Planning, Financing. Geneva, Swizerand: World Health Organization; 2020.
2. Kebede AH, Alebachew Z, Tsegaye F, et al. The first population-based national tuberculosis prevalence survey in Ethiopia, 2010-2011. Int J Tuberc Lung Dis. 2014;18(6):635-639. doi:10.5588/ijtld.13.0417

3. Oren E, Narita M, Nolan C, Mayer J. Neighborhood socioeconomic position and tuberculosis transmission: a Retrospective Cohort Study. BMC Infect Dis. 2014;14(1):227. doi:10.1186/1471-2334-14-227

4. Boccia D, Hargreaves J, De Stavola BL, et al. The association between household socioeconomic position and prevalent tuberculosis in Zambia: a Case-Control Study. PLoS One. 2011;6(6):e20824. doi:10.1371/journal.pone.0020824

5. Santos MLSG, Vendramini SHF, Gazetta CE, Oliveira SAC, Villa TCS. Poverty: socioeconomic characterization at tuberculosis. Rev Latino Am Enfermagem. 2007;15(número especial):762-767. doi:10.1590/S0104-11692007000700008

6. Maciel ELN, Pan W, Dietze R, et al. Spatial patterns of pulmonary tuberculosis incidence and their relationship to socio-economic status in Vitoria, Brazil. Int J Tuberc Lung Dis. 2010;14(11):1395-1402.

7. Cambanis A, Yassin MA, Ramsay A, Squire SB, Arbide I, Cuevas LE. Rural poverty and delayed presentation to tuberculosis services in Ethiopia. Trop Med Int Health. 2005;10(4):330-335. doi:10.1111/j.1365-3156.2005.01393.x

8. Asres A, Jerene D, Deressa W. Pre- and post-diagnosis costs of tuberculosis to patients on directly observed treatment short course in districts of southwestern Ethiopia: a Longitudinal Study. $J$ Health Popul Nutr. 2018;37(1):15. doi:10.1186/s41043-018-0146-0

9. Getahun B, Wubie M, Dejenu G, et al. Tuberculosis care strategies and their economic consequences for patients: the missing link to end tuberculosis. Infect Dis Poverty. 2016;5(1):93. doi:10.1186/s40249016-0187-9

10. Foster N, Vassall A, Cleary S, et al. The economic burden of TB diagnosis and treatment in South Africa. Soc Sci Med. 2015;130:42-50. doi:10.1016/j.socscimed.2015.01.046

11. Ukwaja KN, Alobu I, Abimbola S, et al. Household catastrophic payments for tuberculosis care in Nigeria: incidence, determinants, and policy implications for universal health coverage. Infect Dis Poverty. 2013;2(1):21. doi:10.1186/2049-9957-2-21

12. Laokri S, Dramaix-Wilmet M, Kassa F, et al. Assessing the economic burden of illness for tuberculosis patients in Benin: determinants and consequences of catastrophic health expenditures and inequities. Trop Med Int Health. 2014;19(10):1249-1258. doi:10.1111/tmi.12365

13. Huang Y, Huang J, Su X, et al. Analysis of the economic burden of diagnosis and treatment on patients with tuberculosis in Bao'an district of Shenzhen City. PLoS One. 2020;15(8):e0237865. doi:10.1371/journal.pone. 0237865

14. FMH. Tuberculosis, Leprosy and TB/HIV Prevention and Control Program Manual. Addis Ababa, Ethiopia: Federal Ministry of Health; 2008.

15. Shargie EB, Yassin MA, Lindtjørn B. Quality control of sputum microscopic examinations for acid fast bacilli in southern Ethiopia. Ethiop J Health Dev. 2005;19(2):104-108.

16. Golub JE, Mohan CI, Comstock GW, Chaisson RE. Active case finding of tuberculosis: historical perspective and future prospects. Int J Tuberc Lung Dis. 2005;9:1183-1203.

17. Woldesemayat EM, Datiko DG, Lindtjørn B. Follow-up of chronic coughers improves tuberculosis case finding: results from a Community Based Cohort Study in southern Ethiopia. PLoS One. 2015;10(2):e0116324. doi:10.1371/journal.pone.0116324

18. Federal Ministry of Health Ethiopia. Health Extension Programme Implementation Guidelines. Addis Ababa, Ethiopia; 2007. [Amharic].

19. Mfinanga GS, Ngadaya E, Mtandu R, et al. The quality of sputum smears microscopy diagnosis of pulmonary tuberculosis in Dar es Salaam, Tanzania. Tanzan Health Res Bull. 2007;9(3):164-168.

20. Yassin MA, Datiko DG, Tulloch O, et al. Innovative community-based approaches doubled tuberculosis case notification and improve treatment outcome in southern Ethiopia. PLoS One. 2013;8(5):e63174. doi:10.1371/journal.pone.0063174 
21. Department of Health. Tuberculosis strategic plan for South Africa 2007-2011. Pretoria, South Africa. Available from: http://www.info. gov.za/view/Down. Accessed July 28, 2021.

22. Floyd K, Skeva J, Nyirenda T, Gausi F, Salaniponi F. Cost and cost-effectiveness of increased community and primary care facility involvement in tuberculosis care in Lilongwe District, Malawi. Int J Tuberc Lung Dis. 2003;7:S29-37.

23. Nganda B, Wang'ombe J, Floyd K, Kangangi J. Cost and cost-effectiveness of increased community and primary care facility involvement in tuberculosis care in Machakos District, Kenya. Int J Tuberc Lung Dis. 2003;7:S14-20.

24. Okello D, Floyd K, Adatu F, Odeke R, Gargioni G. Cost and cost-effectiveness of community-based care for tuberculosis patients in rural Uganda. Int J Tuberc Lung Dis. 2003;7:S72-79.

25. Sinanovic E, Floyd K, Dudley L, et al. Cost and cost-effectiveness of community-based care for tuberculosis in Cape Town, South Africa. Int J Tuberc Lung Dis. 2003;7:S56-62.
26. Yadav RP, Nishikiori N, Satha P, Eang MT, Lubell Y. Costeffectiveness of a tuberculosis active case finding program targeting household and neighborhood contacts in Cambodia. Am J Trop Med Hyg. 2014;90(5):866-872. doi:10.4269/ajtmh.13-0419

27. Datiko DG, Lindtjørn B. Cost and cost-effectiveness of treating smear-positive tuberculosis by health extension workers in Ethiopia: an ancillary cost-effectiveness analysis of community randomized trial. PLoS One. 2010;5(2):e9158. doi:10.1371/journal.pone.0009158

28. Wandwalo E, Robberstad B, Morkve O. Cost and cost-effectiveness of community based and health facility based directly observed treatment of tuberculosis in Dar es Salaam, Tanzania. Cost Eff Resour Alloc. 2005;3(1):6. doi:10.1186/1478-7547-3-6
ClinicoEconomics and Outcomes Research

\section{Publish your work in this journal}

ClinicoEconomics and Outcomes Research is an international, peerreviewed open-access journal focusing on Health Technology Assessment, Pharmacoeconomics and Outcomes Research in the areas of diagnosis, medical devices, and clinical, surgical and pharmacological intervention. The economic impact of health policy and health systems

\section{Dovepress}

organization also constitute important areas of coverage. The manuscript management system is completely online and includes a very quick and fair peer-review system, which is all easy to use. Visit http://www.dovepress.com/testimonials.php to read real quotes from published authors. 